\title{
Seleção de fungos filamentosos e de resíduos agroindustriais para a produção de enzimas de interesse biotecnológico
}

\section{Filamentous fungi and agro-industrial residues selection for enzyme production of biotechnological interest}

\author{
Erivelton César Stroparo'; Susan Michelz Beitel'; \\ Juliano Tadeu Vilela de Resende ${ }^{3}$; Adriana $\mathrm{Knob}^{4 *}$
}

Resumo

\begin{abstract}
Muitas enzimas produzidas por fungos têm relevantes aplicações em diferentes áreas industriais. $\mathrm{O}$ objetivo deste trabalho foi selecionar fungos filamentosos produtores de enzimas hidrolíticas, bem como estabelecer os resíduos agroindustriais capazes de induzir maiores níveis de produção. As atividades xilanásica, endoglucanásica, amilásica e poligalacturonásica foram determinadas incubandose os filtrados de cultura com seus respectivos substratos. Posteriormente, a determinação de açúcares redutores foi realizada utilizando-se o reagente ácido 3,5-dinitrosalicílico. A determinação de proteínas foi realizada segundo o método de Bradford modificado. Dentre as linhagens fúngicas avaliadas, Aspergillus niger $\mathrm{J} 4$ apresentou maiores níveis de produção de xilanases $(8,73 \pm 0,34 \mathrm{U} / \mathrm{mL})$ e esta foi maior quando o bagaço de malte foi utilizado como substrato $(9,80 \pm 0,02 \mathrm{U} / \mathrm{mL})$. Penicillium miczynskii produziu os índices mais elevados de atividade endoglucanásica $(0,13 \pm 0,03 \mathrm{U} / \mathrm{mL})$, sendo está última favorecida na presença de casca de abacaxi $(0,18 \pm 0,02 \mathrm{U} / \mathrm{mL})$. Em relação à amilase, A. niger J26 foi selecionada como a melhor linhagem produtora $(6,10 \pm 0,30 \mathrm{U} / \mathrm{mL})$, sendo o farelo de trigo estabelecido como o melhor substrato indutor de sua produção $(7,32 \pm 0,14 \mathrm{U} / \mathrm{mL})$. Penicillium verruculosum exibiu os maiores níveis de atividade poligalacturonásica $(8,65 \pm 0,12 \mathrm{U} / \mathrm{mL})$, especialmente quando cultivado em presença de casca de laranja $(10,32 \pm 0,10 \mathrm{U} / \mathrm{mL})$. O emprego destes resíduos no processo de produção destas enzimas poderá não apenas reduzir seus custos de produção, como também diminuir, substancialmente, o impacto ambiental causado pela deposição destes resíduos no ambiente.

Palavras-chave: Linhagens fúngicas, hidrolases, substratos lignocelulósicos, amiláceos, substâncias pécticas
\end{abstract}

\begin{abstract}
Many fungal enzymes have relevant applications in different industrial areas. The objective of this work was to select fungi producing hydrolytic enzymes, as well as establish agro-industrial wastes capable of inducing higher production levels. Xylanase, endoglucanase, amylase and poligalacturonase activities were determined by incubating the culture filtrates with their respective substrates. Subsequently, the reducing sugars determination was carried out using 3,5-dinitrosalicylic acid reagent. The protein determination was performed according the modified Bradford method. Among the fungal strains evaluated, Aspergillus niger $\mathrm{J} 4$ showed higher levels of xylanase production $(8.73 \pm 0.34 \mathrm{U} / \mathrm{ml})$ and this
\end{abstract}

\footnotetext{
${ }^{1}$ Químico; Mestrando do Programa de Pós-Graduação em Bioenergia, Universidade Estadual do Centro-Oeste, UNICENTRO, Guarapuava, PR. E-mail: stroparo.erivelton@gmail.com

${ }^{2}$ Bióloga; Mestranda do Programa de Pós-Graduação em Biologia Evolutiva, UNICENTRO, Guarapuava, PR. E-mail: susan_ mibe@hotmail.com

${ }^{3}$ Eng $^{\mathrm{o}} \mathrm{Agr}^{\mathrm{o}}$, Prof. Dr. Titular do Dept ${ }^{\mathrm{o}}$ de Agronomia, UNICENTRO, Guarapuava, PR. E-mail: jvresende@uol.com.br

${ }^{4}$ Bióloga; Prof ${ }^{\mathrm{a}}$ Dr $^{\mathrm{a}}$ Titular do Dept ${ }^{\mathrm{o}}$ de Ciências Biológicas, UNICENTRO, Guarapuava, PR. E-mail: knob@unicentro.br

* Autor para correspondência
} 
was greatest when brewer's spent grain was used as substrate $(9.80 \pm 0.02 \mathrm{U} / \mathrm{ml})$. Penicillium miczynskii produced the highest levels of endoglucanasic activity $(0.13 \pm 0.03 \mathrm{U} / \mathrm{ml})$, which, in turn, was favored in the pineapple peel presence $(0.18 \pm 0.02 \mathrm{U} / \mathrm{ml})$. In relation to amylase, A. niger $\mathrm{J} 26$ was selected as the best producer strain $(6.10 \pm 0.30 \mathrm{U} / \mathrm{ml})$ with wheat bran as the best substrate for their production $(7.32$ $\pm 0.14 \mathrm{U} / \mathrm{ml})$. Penicillium verruculosum exhibited the highest level of poligalacturonase activity $(8.65 \pm$ $0.12 \mathrm{U} / \mathrm{ml}))$, especially when grown in orange peel presence $(10.32 \pm 0.10 \mathrm{U} / \mathrm{ml})$. These residues use in these enzymes production may not only reduce their production cost, but also substantially reduce the environmental impact caused by the deposition of these wastes on the environment.

Key words: Fungal strains, hydrolases, lignocellulosic and amylaceous substrates, pectic substances

\section{Introdução}

Dentre um grande número de microrganismos não patogênicos capazes de produzir enzimas úteis, os fungos filamentosos se destacam devido à sua facilidade de cultivo, por secretarem suas enzimas diretamente no meio em que se encontram, não necessitando de ruptura celular para sua liberação. Adicionalmente, apresentam elevados níveis de produção enzimática, com grande potencial para diversas aplicações industriais (POLIZELI et al., 2005, GUIMARÃES et al., 2006).

Amilases são enzimas capazes de hidrolisar as ligações glicosídicas $\alpha-1,4$ e $\alpha-1,6$ do amido, resultando em diversos produtos, incluindo dextrinas e progressivamente pequenos polímeros compostos de unidades de glicose (GUPTA et al., 2003; PANDEY et al., 2005). Apresentam potencial de aplicação em um grande número de processos industriais, tais como nas indústrias alimentícias, têxteis, de papel, detergentes e farmacêuticas (SIVARAMAKRISHNAN et al., 2006; SOUZA; MAGALHÃES, 2010).

As xilanases são as principais enzimas no processo de despolimerização da xilana, a principal hemicelulose da parede celular dos vegetais. Estas enzimas hidrolisam as ligações glicosídicas internas ao longo da cadeia da xilana, promovendo a liberação de xilooligossacarídeos de vários tamanhos. Enzimas xilanolíticas apresentam aplicações na conversão de materiais lignocelulósicos em produtos químicos e combustíveis, nas indústrias de alimentos, têxteis e de ração animal, no branqueamento da celulose e do papel, entre outras (POLIZELLI et al., 2005;
MOURE et al., 2006, KNOB; TERRASAN; CARMONA, 2010).

As endoglucanases hidrolisam as ligações beta1,4 acessíveis no interior da molécula da celulose e geram novas terminações de cadeia (LYND et al., 2002). A habilidade em decompor a biomassa celulósica em glicose, a qual poderá ser convertida em produtos de valor agregado e energia, tem tornado as celulases um dos sistemas enzimáticos multicomponentes mais investigados (ADSUL et al., 2005; CASTRO; PEREIRA JUNIOR, 2010). Além desta aplicação específica, as celulases são amplamente utilizadas no descoramento e amaciamento de tecidos, formulações de detergentes domésticos e industriais, na produção de sucos, preparação de alimentos infantis, produtos dermatológicos e rações animais (SUKIMARAN; REETA; PANDEY, 2005; ZHANG; HIMMEL; MIELENZ, 2006, KUHAD; GUPTA; SINGH, 2011).

Poligalacturonases correspondem a um grupo de enzimas que atuam sobre as substâncias pécticas, por meio de reações de hidrólise e de trans-eliminação, provocando a despolimerização das moléculas, e por meio de reações de desesterificação, hidrolisando a ligação éster entre os grupos carboxila e metil das pectinas. Estas enzimas hidrolisam preferencialmente o pectato ao invés da pectina, resultando na liberação de mono ou dissacarídeos (KASHYAP et al., 2001). Algumas das aplicações destas enzimas nas indústrias de alimentos incluem amadurecimento de frutas, clarificação e redução de viscosidade em sucos de frutas e tratamento preliminar do suco de uva para indústrias vinícolas. 
Ainda podem ser citadas a extração de polpa de tomate, fermentação de chá e chocolate, tratamento de resíduos vegetais, degomagem de fibras nas indústrias têxtil e de papel, nutrição animal, enriquecimento protéico de alimentos infantis e extração de óleos (NIGHOJKAR et al., 2006; GUPTA et al., 2007; USTOK; TARI; GOGUS, 2007; PRATHYUSHA; SUNEETHA, 2011).

Nos últimos anos, há um interesse crescente no uso eficiente de diversos resíduos agroindustriais. Vários bioprocessos têm sido desenvolvidos utilizando estes materiais como substratos para a produção de diversas moléculas com alto valor agregado, tais como proteínas microbianas, ácidos orgânicos, etanol, enzimas e metabólitos secundários biologicamente ativos (SANCHÉS, 2009). O uso de resíduos agrícolas como substratos em bioprocessos, além de ser economicamente viável, pode ajudar a resolver os problemas ambientais decorrentes do seu acúmulo na natureza (DASHTBAN; SCHARAFT; WENSHENG, 2009; ALVIRA et al., 2010).

Atualmente, apesar de o processo enzimático de hidrólise ser considerado de grande potencialidade, este enfrenta vários gargalos tecnológicos, sendo o custo de produção um dos pontos mais avaliados. Dentre as alternativas existentes a fim de diminuir estes custos, está o emprego de resíduos agroindustriais, geralmente descartados pela indústria, o qual se mostra uma fonte riquíssima de substratos para aplicação neste processo (MURUGAN et al., 2011). Por estas razões, este trabalho teve por objetivo estabelecer os melhores resíduos agroindustriais capazes de induzir a produção de hidrolases, por linhagens de fungos filamentosos previamente selecionadas como melhor produtoras destas enzimas.

\section{Material e Métodos}

\section{Linhagens, cultivo e manutenção}

Os estudos foram conduzidos no Laboratório de Microbiologia do Departamento de Ciências
Biológicas da Universidade Estadual do CentroOeste. Os fungos avaliados quanto à produção de enzimas hidrolíticas foram Penicillium glabrum $\mathrm{J} 3, P$. glabrum J11, Penicillium verruculosum, Penicillium herquei, Penicillium miczynskii, Trichoderma viride, Aspergillus niger J4 e A. niger J26. Todas as linhagens pertencem à coleção de cultura do Centro de Estudos Ambientais - CEA/UNESP. Os fungos foram mantidos em laboratório em meio sólido de Vogel (VOGEL, 1956), suplementado com glicose como fonte de carbono, na concentração de 1,5\% $(\mathrm{m} / \mathrm{v})$. Repiques das culturas foram realizados periodicamente, sendo incubadas a $28{ }^{\circ} \mathrm{C}$, por sete dias. Após este período, as linhagens foram utilizadas ou armazenadas a $4{ }^{\circ} \mathrm{C}$.

\section{Obtenção das preparações enzimáticas}

Conídios das linhagens fúngicas cultivados em meio sólido de Vogel, a $28^{\circ} \mathrm{C}$, por sete dias foram suspensos em água destilada esterilizada, sendo a suspensão filtrada em lã de vidro estéril para a remoção dos fragmentos de hifas, e suas concentrações ajustadas em Câmara de Neubauer para $1,0 \times 10^{7}$ conídios $/ \mathrm{mL}$. Um mililitro dessa suspensão foi inoculado em frascos Erlenmeyers de $125 \mathrm{~mL}$, contendo $25 \mathrm{~mL}$ de meio líquido de Vogel, suplementado a $1 \%$ com diferentes fontes de carbono, de acordo com cada experimento. Após o crescimento em meio liquido por períodos préestabelecidos, as culturas foram filtradas a vácuo em funil de Büchner. Desta forma, foram obtidos os filtrados dos meios de cultivo livres de células, os quais foram utilizados como fonte de enzimas e de proteínas extracelulares. Todos os cultivos foram realizados em duplicata.

\section{Extração de proteinas intracelulares}

Os micélios, também obtidos pela filtração, foram previamente congelados e triturados com três partes de areia lavada $(\mathrm{m} / \mathrm{m})$, com auxílio de almofariz e pistilo. Posteriormente, 15 partes 
de tampão apropriado foram adicionadas, para cada parte de micélio seco $(\mathrm{v} / \mathrm{m})$. As misturas foram centrifugadas $(7500 \mathrm{~g}, 20$ minutos) e os sobrenadantes obtidos foram utilizados como fonte de proteínas intracelulares.

\section{Determinação da atividade xilanásica}

A atividade xilanase foi determinada utilizandose como substrato uma solução $1 \%(\mathrm{~m} / \mathrm{v})$ de xilano de birchwood, em tampão McIlvaine, $\mathrm{pH}$ 6,5. A mistura de reação foi incubada em banho-Maria a 50 ${ }^{\circ} \mathrm{C}$. Em intervalos de tempo apropriados, a reação foi interrompida pela adição de $250 \mathrm{~mL}$ do reagente de ácido 3,5-dinitrosalicílico (ADNS). A determinação de açúcares redutores liberados foi realizada pelo método de Miller (1959), utilizando-se a xilose como padrão. Uma unidade de atividade enzimática foi definida como correspondendo à liberação de $1 \mu \mathrm{mol}$ de açúcar redutor equivalente à xilose, por minuto por $\mathrm{mL}$ de amostra, nas condições de ensaio.

\section{Determinação da atividade endoglucanásica}

A determinação da atividade endoglucanásica foi realizada de acordo com o método proposto por Ghose (1987), utilizando-se uma solução 1\% de carboximetilcelulose em tampão Mcllvaine $\mathrm{pH} 5,0$, a $50{ }^{\circ} \mathrm{C}$. Após períodos determinados, a determinação de açúcares redutores foi realizada pelo método de Miller (1959), utilizando-se a glicose como padrão. Uma unidade de atividade foi definida como a quantidade de enzima capaz de liberar $1 \mu \mathrm{mol}$ de grupos redutores por minuto, nas condições de ensaio.

\section{Determinação da atividade amilásica}

A atividade amilásica foi determinada utilizandose como substrato uma solução $1 \%(\mathrm{~m} / \mathrm{v})$ de amido, em tampão McIlvaine, pH 6,0. A mistura de reação foi incubada em banho-Maria a $50{ }^{\circ} \mathrm{C}$. Em intervalos de tempo apropriados, a reação foi interrompida e a determinação de açúcares redutores liberados foi realizada de acordo com Miller (1959). Uma unidade de atividade enzimática foi definida como correspondendo à liberação de $1 \mu \mathrm{mol}$ de açúcar redutor equivalente à glicose, por minuto por $\mathrm{mL}$ de amostra, nas condições de ensaio.

\section{Determinação da atividade poligalacturonásica}

A atividade poligalacturonase foi determinada por meio de incubação da enzima com ácido poligalacturônico em tampão acetato de sódio $0,05 \mathrm{M}, \mathrm{pH} 5,5$, a $50{ }^{\circ} \mathrm{C}$. Em intervalos de tempo adequados, a reação foi interrompida com o reagente ADNS, e o substrato não hidrolisado foi separado da mistura por meio de centrifugação. Em seguida, foi realizada a determinação de açúcares redutores (MILLER, 1959), utilizando-se ácido galacturônico como padrão. Uma unidade de atividade foi definida como a quantidade de enzima capaz de liberar 1 $\mu$ mol de grupos redutores por minuto.

\section{Determinação de proteínas totais}

As proteínas foram determinadas a partir do método colorimétrico de Bradford modificado (SEDMAK; GROSSEBERG, 1977), utilizando soro albumina bovina como padrão. Todos os ensaios foram realizados em duplicata.

\section{Avaliação das linhagens fúngicas quanto ao} potencial de produção de hidrolases

Para avaliar a produção de amilases e de xilanases, as linhagens fúngicas foram crescidas em meio líquido de Vogel, pH 6,5, a $28^{\circ} \mathrm{C}$, suplementado com $1 \%$ de amido solúvel e 1\% de xilano de birchwood, respectivamente, por cinco dias. Para a obtenção de poligalacturonases e endoglucanases, os fungos foram cultivados em meio líquido de Vogel, $\mathrm{pH}$ 6,5, a $28{ }^{\circ} \mathrm{C}$, suplementado com $1 \%$ de pectina de citrus e carboximetilcelulose, por seis e 10 dias de cultivo, respectivamente. 
Influência de diferentes resíduos agroindustriais sobre a produção de hidrolases

As melhores linhagens fúngicas previamente selecionadas foram cultivadas em meio líquido de Vogel, $\mathrm{pH}$ 6,5, de forma estacionária, a temperatura de $28{ }^{\circ} \mathrm{C}$, em presença de diferentes fontes de carbono a $1 \%(\mathrm{~m} / \mathrm{v})$ a fim de se determinar quais substratos foram capazes de induzir a maior produção das enzimas avaliadas. O período de incubação para a produção de cada enzima foi o mesmo que o especificado no item anterior.

\section{Resultados e Discussão}

Ao avaliar diferentes linhagens fúngicas quanto ao potencial de produção de hidrolases (Tabela $1)$, verifica-se que os maiores níveis de atividade xilanásica foram produzidos pelas linhagens $A$. niger $\mathrm{J} 4(8,73 \pm 0,34 \mathrm{U} / \mathrm{mL})$ e $T$. viride $(6,65 \pm$ $0,23 \mathrm{U} / \mathrm{mL})$. Quanto à produção de endoglucanase, $P$. miczynskii apresentou os índices mais elevados $(0,13 \pm 0,03 \mathrm{U} / \mathrm{mL})$, seguido por $A$. niger $\mathrm{J} 4$ $(0,11 \pm 0,04 \mathrm{U} / \mathrm{mL})$. Os fungos $A$. niger $\mathrm{J} 26$ e $P$. glabrum J3 foram os que mais produziram amilases, correspondendo a $6,10 \pm 0,30 \mathrm{U} / \mathrm{mL}$ e 4,87 $\pm 0,07 \mathrm{U} /$ $\mathrm{mL}$, respectivamente, enquanto que a produção de poligalacturonases por $P$. verruculosum foi superior diante das demais linhagens avaliadas $(8,65 \pm 0,12$ $\mathrm{U} / \mathrm{mL}$ ).

Alguns fungos não foram capazes de produzir enzimas, como $P$. verruculosum, cuja atividade amilásica não foi detectada, $P$. herquei, o qual não foi capaz de produzir xilanases e P. glabrum J3, o qual não foi capaz de produzir endoglucanases. Verifica-se ainda que as diferentes linhagens de $P$. glabrum e A. niger diferiram quanto ao potencial de produção e/ou níveis de enzimas produzidas. De acordo com Underklofer, Barton e Rennert (1958), as quantidades absolutas e relativas de cada enzima produzida podem variar consideravelmente entre espécies e mesmo entre linhagens da mesma espécie. As características físico-químicas das enzimas produzidas também podem diferir, visto que diferentes microrganismos e linhagens se comportam de maneira variada frente a uma mesma condição de incubação, podendo produzir enzimas com propriedades diversas.

Tabela 1. Produção de enzimas hidrolíticas* por diferentes linhagens de fungos filamentosos.

\begin{tabular}{lcccc}
\hline \multirow{2}{*}{ Linhagens fúngicas } & \multicolumn{3}{c}{ Atividade enzimática $(\mathbf{U} / \mathbf{m L})$} \\
\cline { 2 - 5 } & Xilanase & Endoglucanase & Amilase & Poligalacturonase \\
\hline P. glabrum J3 & $0,54 \pm 0,09$ & $\mathrm{ND}$ & $4,87 \pm 0,07$ & $0,21 \pm 0,03$ \\
P. glabrum J11 & $0,62 \pm 0,12$ & $0,05 \pm 0,00$ & $2,34 \pm 0,08$ & $0,63 \pm 0,05$ \\
P. verruculosum & $4,62 \pm 0,35$ & $0,03 \pm 0,00$ & $\mathrm{ND}$ & $8,65 \pm 0,12$ \\
P. herquei & $\mathrm{ND}$ & $0,09 \pm 0,01$ & $2,35 \pm 0,08$ & $6,43 \pm 0,43$ \\
P. miczynskii & $0,69 \pm 0,09$ & $0,13 \pm 0,03$ & $0,14 \pm 0,02$ & $1,04 \pm 0,12$ \\
T. viride & $6,65 \pm 0,23$ & $0,04 \pm 0,00$ & $0,21 \pm 0,02$ & $3,23 \pm 0,23$ \\
A. niger J4 & $8,73 \pm 0,34$ & $0,11 \pm 0,04$ & $4,13 \pm 0,12$ & $6,53 \pm 0,45$ \\
A. niger J26 & $5,77 \pm 0,67$ & $0,06 \pm 0,05$ & $6,10 \pm 0,30$ & $4,54 \pm 0,32$ \\
\hline
\end{tabular}

$\mathrm{ND}=$ atividade enzimática não detectada.

* em meio base líquido de Vogel e cultivos em duplicata.

Fonte: Elaboração dos autores. 
Após a seleção das melhores linhagens produtoras, estas foram cultivadas em presença de diferentes resíduos agroindustriais para o estabelecimento dos melhores substratos indutores de sua produção. A maior produção de xilanases (Tabela 2), tanto em unidades por $\mathrm{mL}(9,80 \pm 0,02)$ quanto específica $(30,71 \pm 0,10 \mathrm{U} / \mathrm{mg}$ proteína $)$ foi verificada em presença de bagaço de malte. Em presença deste substrato, A. niger J4 também apresentou melhor crescimento, revelado pelo teor de proteínas intracelulares produzidas.

Tabela 2. Efeito de diferentes resíduos agroindustriais sobre a produção de xilanases* por A. niger J4.

\begin{tabular}{lccc}
\hline $\begin{array}{c}\text { Fonte de Carbono }(1 \% \\
\text { peso/v) }\end{array}$ & $\begin{array}{c}\text { Proteína Intracelular } \\
(\mathrm{mg})\end{array}$ & $\begin{array}{c}\text { Atividade Enzimática } \\
(\mathrm{U} / \mathrm{mL})\end{array}$ & $\begin{array}{c}\text { Atividade Específica }(\mathrm{U} / \mathrm{mg} \\
\text { proteína })\end{array}$ \\
\hline Farelo de trigo & $3,05 \pm 0,06$ & $2,32 \pm 0,03$ & $7,93 \pm 0,04$ \\
Casca de maçã & $3,61 \pm 0,04$ & $3,31 \pm 0,05$ & $12,43 \pm 0,12$ \\
Bagaço de malte & $3,57 \pm 0,01$ & $9,80 \pm 0,02$ & $30,71 \pm 0,10$ \\
Farelo de maracujá & $3,96 \pm 0,02$ & $3,28 \pm 0,02$ & $8,11 \pm 0,13$ \\
Casca de laranja & $0,81 \pm 0,03$ & $0,60 \pm 0,02$ & $2,40 \pm 0,12$ \\
Casca de abacaxi & $4,80 \pm 0,01$ & $6,07 \pm 0,09$ & $27,48 \pm 0,23$ \\
Bagaço de cana & $3,18 \pm 0,05$ & $\mathrm{ND}$ & $\mathrm{ND}$ \\
Sabugo de milho & $\mathrm{ND}$ & $\mathrm{ND}$ & $\mathrm{ND}$ \\
Casca de arroz & $\mathrm{ND}$ & $\mathrm{ND}$ & $\mathrm{ND}$ \\
Casca de soja & $1,23 \pm 0,05$ & $0,33 \pm 0,01$ & $1,76 \pm 0,02$ \\
Palha de milho & $0,87 \pm 0,02$ & $\mathrm{ND}$ & $\mathrm{ND}$ \\
Xilano & $4,20 \pm 0,03$ & $1,39 \pm 0,05$ & $5,39 \pm 0,09$ \\
\hline
\end{tabular}

ND = atividade enzimática não detectada.

* substrato, solução $1 \%(\mathrm{~m} / \mathrm{v})$ de xilano de birchwood em tampão de McIlvaine $\mathrm{pH}$ 6,5, 50 $\mathrm{C}$, determinações em duplicata.

Fonte: Elaboração dos autores.

A produção de enzimas xilanolíticas usando bagaço de malte como substrato foi previamente descrita por Terrasan et al. (2010), por Penicillium janczewskii. A utilização do principal resíduo da indústria cervejeira como substrato para a produção de enzimas mostra-se interessante, uma vez que grandes quantidades são geradas anualmente (ALIYU ; BALA, 2011). No Brasil, a geração anual de bagaço de malte corresponde aproximadamente a 1,7 milhões de toneladas (MUSSATTO; ROBERTO, 2006). Além disso, este resíduo tem recebido pouca atenção como um produto de baixo custo e sua aplicação até agora tem sido limitada, sendo aplicado especialmente em rações animais (MUSSATTO; ROBERTO, 2005).

O segundo melhor substrato indutor da produção de xilanases por $A$. niger $\mathrm{J} 4$ foi a casca de abacaxi, correspondendo a $6,07 \pm 0,09 \mathrm{U} / \mathrm{mL}$ e 27,48 $\pm 0,23$ $\mathrm{U} / \mathrm{mg}$ proteína. Baixos níveis de produção foram verificados em presença de casca de laranja e palha de milho, enquanto que em presença de bagaço de cana, sabugo de milho e palha de arroz a produção de xilanases não foi detectada. Contrariamente, linhagens de Penicillium janthinellum, Thermoascus aurantiacus e Sporotrichum thermophile mostraram-se capazes de crescer em presença de bagaço de cana e produzir xilanases (PALMA et al., 1996; SILVA et al., 2005; KATAPODIS; CHRISTAKOPOULOU; CHRISTAKOPOULOS, 2006). Irfan et al. (2010) reportaram a produção de xilanases utilizando bagaço de cana como substrato por uma outra linhagem de A. niger, assim como Milagres et al. (2004), para uma linhagem de Thermoascus aurantiacus. 
A produção de endoglucanases por $P$. miczninscii usando diferentes resíduos agroindustriais está demonstrada na Tabela 3. Observa-se que, dentre os substratos avaliados, maior produção em unidades por volume foi obtida quando $P$. miczninscii foi crescido em presença de casca de abacaxi $(0,18$ $\mathrm{U} / \mathrm{mL})$ e casca de laranja $(0,15 \mathrm{U} / \mathrm{mL})$. Nestes substratos foram obtidos também os maiores valores de proteínas intracelulares, revelando que os mesmos propiciaram bom desenvolvimento fúngico. P. miczninscii também se desenvolveu bem em presença de farelo de maracujá, porém neste caso a produção de endoglucanases foi inferior, quando comparada as demais fontes de carbono avaliadas.

Tabela 3. Efeito de diferentes resíduos agroindustriais sobre a produção de endoglucanases* por $P$. miczninscii.

\begin{tabular}{lccc}
\hline $\begin{array}{c}\text { Fonte de Carbono }(1 \% \\
\text { peso/v) }\end{array}$ & $\begin{array}{c}\text { Proteína Intracelular } \\
(\mathrm{mg})\end{array}$ & $\begin{array}{c}\text { Atividade Enzimática } \\
(\mathrm{U} / \mathrm{mL})\end{array}$ & $\begin{array}{c}\text { Atividade Específica }(\mathrm{U} / \mathrm{mg} \\
\text { proteína })\end{array}$ \\
\hline Farelo de trigo & $0,36 \pm 0,01$ & $0,10 \pm 0,02$ & $0,81 \pm 0,07$ \\
Casca de maçã & $0,38 \pm 0,02$ & $0,12 \pm 0,02$ & $3,65 \pm 0,71$ \\
Bagaço de malte & $0,20 \pm 0,03$ & $0,07 \pm 0,00$ & $5,57 \pm 0,32$ \\
Farelo de maracujá & $0,53 \pm 0,06$ & $0,05 \pm 0,00$ & $2,37 \pm 0,12$ \\
Casca de laranja & $0,49 \pm 0,06$ & $0,15 \pm 0,01$ & $4,06 \pm 0,25$ \\
Casca de abacaxi & $0,43 \pm 0,04$ & $0,18 \pm 0,02$ & $6,64 \pm 0,36$ \\
Bagaço de cana & $0,20 \pm 0,01$ & $\mathrm{ND}$ & $\mathrm{ND}$ \\
Sabugo de Milho & $0,17 \pm 0,01$ & $\mathrm{ND}$ & $\mathrm{ND}$ \\
Casca de arroz & $0,03 \pm 0,00$ & $\mathrm{ND}$ & $\mathrm{ND}$ \\
Casca de soja & $0,19 \pm 0,02$ & $0,06 \pm 0,00$ & 0,6 \\
Palha de cana & $0,11 \pm 0,00$ & $\mathrm{ND}$ & $\mathrm{ND}$ \\
Palha de milho & $0,06 \pm 0,00$ & $\mathrm{ND}$ & $\mathrm{ND}$ \\
\hline
\end{tabular}

$\mathrm{ND}=$ atividade enzimática não detectada.

* substrato, solução $1 \%$ de carboximetilcelulose em tampão McIlvaine pH 5,0, $50{ }^{\circ} \mathrm{C}$, determinações em duplicata.

Fonte: Elaboração dos autores.

A produção de endoglucanases utilizando casca de laranja como fonte de carbono por Rhizopus oryzae foi relatada por Karmakar e Ray (2010). No entanto, até o presente momento, apenas um trabalho na literatura relata a produção de enzimas celulolíticas utilizando casca e polpa de acabaxi como substrato (OMOJASOLA; JILANI; IBIYEMI, 2008). O emprego da casca de abacaxi para a produção de endoglucanases por $P$. miczninscii também se mostra bastante promissor, visto que o Brasil destaca-se atualmente como o maior produtor de abacaxi entre os países tropicais (FAOSTAT, 2010), resultando em uma quantidade considerável de resíduos que podem ser transformados em produtos de maior valor agregado.

Níveis intermediários de endoglucanases foram obtidos por meio da utilização de casca de maçã e do farelo de trigo. No entanto, os substratos bagaço de cana, sabugo de milho, casca de arroz, palha de cana e palha de milho não favoreceram a produção destas enzimas por P. miczninscii. As diferenças nos níveis de produção observados entre os resíduos agroindustriais podem estar relacionadas a diferenças em sua composição, bem como a diferenças na acessibilidade dos substratos pelas linhagens fúngicas.

Ao avaliar o efeito de diversos resíduos lignocelulósicos sobre a produção de amilases por A. niger J26 (Tabela 4), verificou-se que níveis mais elevados de atividade foram detectados em meio suplementado com farelo de trigo $(6,32 \mathrm{U} / \mathrm{mL}$ e 33,20 U/mg proteína). A síntese de amilases em níveis mais elevados também ocorreu em presença de bagaço de malte. Similarmente, ao estudar 
a produção de amilases por $A$. oryzae, Tunga e Tunga (2003) verificaram que os maiores níveis de produção foram obtidos quando este fungo foi cultivado em presença de farelo de trigo. Este também foi o melhor substrato para a produção de amilases por Penicillium chrysogenum (BALKAN; ERTAN, 2007). Segundo Vijayaraghavan, Remya e Prakash (2011), na maioria dos estudos, o farelo de trigo tem sido o substrato de escolha para a indução de amilases.

Tabela 4. Efeito de diferentes resíduos agroindustriais sobre a produção de amilases* por A. niger J26.

\begin{tabular}{lccc}
\hline $\begin{array}{c}\text { Fonte de Carbono }(1 \% \\
\text { peso/v) }\end{array}$ & $\begin{array}{c}\text { Proteína Intracelular } \\
(\mathrm{mg})\end{array}$ & $\begin{array}{c}\text { Atividade Enzimática } \\
(\mathrm{U} / \mathrm{mL})\end{array}$ & $\begin{array}{c}\text { Atividade Específica (U/ } \\
\text { mg proteína })\end{array}$ \\
\hline Farelo de trigo & $1,15 \pm 0,07$ & $6,32 \pm 0,14$ & $33,20 \pm 1,23$ \\
Casca de maçã & $1,09 \pm 0,03$ & $2,15 \pm 0,05$ & $21,08 \pm 3,23$ \\
Bagaço de malte & $0,34 \pm 0,03$ & $5,11 \pm 0,27$ & $20,32 \pm 0,55$ \\
Farelo de maracujá & $0,94 \pm 0,08$ & $1,65 \pm 0,00$ & $1,23 \pm 0,09$ \\
Casca de laranja & $0,29 \pm 0,06$ & $2,03 \pm 0,12$ & $3,43 \pm 0,19$ \\
Casca de abacaxi & $0,97 \pm 0,04$ & $1,26 \pm 0,09$ & $2,64 \pm 0,13$ \\
Bagaço de cana & $0,27 \pm 0,01$ & $0,12 \pm 0,02$ & $0,76 \pm 0,03$ \\
Sabugo de milho & $0,97 \pm 0,01$ & $\mathrm{ND}$ & $\mathrm{ND}$ \\
Casca de arroz & $0,23 \pm 0,02$ & $1,24 \pm 0,19$ & $9,31 \pm 0,26$ \\
Casca de soja & $0,17 \pm 0,02$ & $1,14 \pm 0,09$ & $5,23 \pm 0,19$ \\
Palha de cana & $0,89 \pm 0,02$ & $0,28 \pm 0,21$ & $1,60 \pm 0,07$ \\
Palha de milho & $0,77 \pm 0,00$ & $0,10 \pm 0,04$ & $1,50 \pm 0,05$ \\
\hline
\end{tabular}

$\mathrm{ND}=$ atividade enzimática não detectada.

* substrato, solução $1 \%(\mathrm{~m} / \mathrm{v})$ de amido em tampão McIlvaine $\mathrm{pH}$ 6,0, $50{ }^{\circ} \mathrm{C}$, determinações em duplicata.

Fonte: Elaboração dos autores.

Apesar do bom desenvolvimento fúngico, os mais baixos níveis de produção ou ausência destes foram obtidos por meio da utilização do sabugo de milho, palha de cana e palha de milho, substratos essencialmente lignocelulósicos, que apresentam baixo teor de amido. De acordo com Gupta et al. (2003), os substratos amiláceos são as principais fontes de carbono empregadas para induzir a síntese e liberação de amilases, podendo ser empregados resíduos agroindustriais ou de processamento do amido, os quais contêm quantidades residuais de amido suficientes para este fim.

Ainfluência de diferentes resíduos agroindustriais sobre a produção de poligalacturonases por $P$. verruculosum está apresentada na Tabela 5 . Verifica-se que os maiores níveis de produtividade enzimática foram obtidos em meios de cultura suplementados com casca de laranja (10,32 \pm
$0,10 \mathrm{U} / \mathrm{mL})$, seguido por casca de abacaxi $(7,45$ $\pm 0,12 \mathrm{U} / \mathrm{mL})$ e casca de maçã $(7,23 \pm 0,27 \mathrm{U} /$ $\mathrm{mL}$ ). A melhor produção de poligalacturonases por Aspergillus niveus também ocorreu em presença de casca de laranja (MALLER et al., 2011). Similarmente, Fusarium moniliforme foi capaz de produzir elevados níveis de poligalacturonases em meio contendo como base este substrato (NITURE; PANT, 2004). Pedrolli et al. (2008) relataram a melhor produção de poligalacturonases por $A$. giganteus em meios suplementados com bagaço de laranja. A produção de poligalacturonases por P. verruculosum utilizando a casca de laranja como substrato seria bastante viável, visto que grandes quantidades deste resíduo são geradas no Brasil, por ser este líder mundial na produção e exportação de suco de laranja concentrado e congelado (IBGE, 2010). 
Tabela 5. Efeito de diferentes resíduos agroindustriais sobre a produção de poligalacturonases*por P. verruculosum.

\begin{tabular}{lccc}
\hline \multicolumn{1}{c}{$\begin{array}{c}\text { Fonte de Carbono } \\
(1 \% \text { peso/v) }\end{array}$} & $\begin{array}{c}\text { Proteína Intracelular } \\
(\mathrm{mg})\end{array}$ & $\begin{array}{c}\text { Atividade Enzimática } \\
(\mathrm{U} / \mathrm{mL})\end{array}$ & $\begin{array}{c}\text { Atividade Específica } \\
(\mathrm{U} / \mathrm{mg} \text { proteína })\end{array}$ \\
\hline Farelo de trigo & $0,84 \pm 0,15$ & $1,23 \pm 0,13$ & $4,33 \pm 0,12$ \\
Casca de maçã & $1,02 \pm 0,19$ & $7,23 \pm 0,27$ & $22,47 \pm 0,23$ \\
Bagaço de malte & $0,73 \pm 0,06$ & $0,45 \pm 0,02$ & $1,23 \pm 0,08$ \\
Farelo de maracujá & $0,89 \pm 0,07$ & $1,23 \pm 0,12$ & $4,32 \pm 0,22$ \\
Casca de laranja & $1,23 \pm 0,12$ & $10,32 \pm 0,10$ & $32,74 \pm 0,25$ \\
Casca de abacaxi & $0,94 \pm 0,09$ & $7,45 \pm 0,12$ & $24,34 \pm 0,12$ \\
Bagaço de cana & $0,34 \pm 0,04$ & $\mathrm{ND}$ & $\mathrm{ND}$ \\
Sabugo de milho & $\mathrm{ND}$ & $\mathrm{ND}$ & $\mathrm{ND}$ \\
Casca de arroz & $0,43 \pm 0,02$ & $\mathrm{ND}$ & $\mathrm{ND}$ \\
Casca de soja & $0,56 \pm 0,03$ & $\mathrm{ND}$ & $\mathrm{ND}$ \\
Palha de cana & $0,12 \pm 0,02$ & $\mathrm{ND}$ & $\mathrm{ND}$ \\
Palha de milho & $0,23 \pm 0,05$ & $\mathrm{ND}$ & $\mathrm{ND}$ \\
\hline
\end{tabular}

ND = atividade enzimática não detectada.

* substrato, ácido poligalacturônico em tampão acetato de sódio $\mathrm{pH}$ 5,0, $50{ }^{\circ} \mathrm{C}$, determinações em duplicata.

Fonte: Elaboração dos autores.

Os resíduos sabugo de milho, bagaço de cana, casca de arroz, casca de soja, palha de cana e palha de milho não foram capazes de induzir a produção de poligalacturonases por $P$. verruculosum. No entanto, a produção de poligalacturonases por fungos filamentos utilizando alguns destes substratos, como bagaço de cana e casca de arroz tem sido descrita na literatura (FREITAS et al., 2006; DAMÁSIO et al., 2011).

\section{Considerações Finais}

De acordo com os estudos realizados, podese concluir que a produção de xilanases por $A$. niger apresentou potencial promissor, utilizando bagaço de malte como substrato. A produção de endoglucanases por $P$. miczninscii utilizando casca de abacaxi como fonte de carbono também foi interessante, assim como a produção de amilases por $A$. niger $\mathrm{J} 26$ em presença de farelo de trigo. Adicionalmente, a obtenção de poligalacturonases a partir de $P$. verruculosum mostrou ser viável, visto que é possível empregar a casca de laranja em sua produção. Além de possibilitar uma importante alternativa para a reciclagem de resíduos agroindustriais, o desenvolvimento destas tecnologias de produção poderá não somente reduzir os custos de produção destas enzimas, como também amenizar os problemas ambientais decorrentes do acúmulo destes resíduos na natureza.

\section{Agradecimentos}

Os autores agradecem a Coordenação de Aperfeiçoamento de Pessoal de Nível Superior (CAPES) pelo suporte financeiro e pela bolsa de estudos concedida ao primeiro autor.

\section{Referências}

ADSUL, M. G.; GHULEB, J. E.; SINGHB, R.; SHAIKHB, H. Enzymatic hydrolysis of delignified bagasse polysaccharides. Carbohydrate Polymers, Amsterdam, v. 62, n. 1, p. 6-10, 2005.

ALIYU, S.; BALA, M. Brewer's spent grain: a review of its potentials and applications. African Journal of Biotechnology, Nairobi, v. 10, n. 3, p. 324-331, 2011.

ALVIRA, P.; TOMÁS-PEJÓ, E.; BALLESTEROS, M.; NEGRO, M. J. Pretreatment technologies for an efficient bioethanol production process based on enzymatic hydrolysis: a review. Bioresource Technology, Essex, v. 101, n. 13, p. 4851-4861, 2010. 
BALKAN, B.; ERTAN, F. Production of $\alpha$-amylase from Penicillium chrysogenum under solid-state fermentation by using some agricultural by-products. Food Technology and Biotechnology, Zagreb, v. 45, n. 4, p. 439-442, 2007.

CASTRO, A. M.; PEREIRA JUNIOR, N. Produção, propriedades e aplicação de celulases na hidrólise de resíduos agroindustriais. Química Nova, São Paulo, v. 33, n. 1, p. 181-188, 2010.

DAMÁSIO, A. R. L.; MALLER, A.; SILVA, T. M.; JORGE, J. A.; TERENZI, H. F.; POLIZELI, M. L. T. M. Biotechnological potential of alternative carbon sources for production of pectinases by Rhizopus microsporus var. rhizopodiformis. Brazilian Archives of Biology and Technology, Curitiba, v. 54, n. 1, p. 141-148, 2011.

DASHTBAN, M.; SCHARAFT, H.; WENSHENG, Q. Fungal bioconversion of lignocellulosic residues; opportunities \& perspectives. International Journal of Biological Sciences, Lake Haven, v. 5, n. 6, p. 578-595, 2009.

FOOD AND AGRICULTURE ORGANIZATION OF THE UNITED NATIONS STATISTICAL DATABASE - FAOSTAT. Crops database in 2010. 2010. Disponível em: <http://faostat.fao.org >. Acesso em: 22 abr. 2012.

FREITAS, P. M.; MARTIN, N.; SILVA, D.; SILVA, R.; GOMES, E. Production and partial characterization of polygalacturonases produced by thermophilic Monascus sp. N8 and by thermotolerant Aspergillus sp. N12 on solidstate fermentation. Brazilian Journal of Microbiology, São Paulo, v. 37, n. 3, p. 302-306, 2006.

GHOSE, T. K. Measurement of cellulase activities. Pure and Applied Chemistry, Oxford, v. 59, n. 2, p. 257-268, 1987.

GUIMARÃES, L. H. S.; PEIXOTO-NOGUEIRA, S. C.; MICHELIN, M.; RIZZATTI, A. C. S.; SANDRIM, V. C.; ZANOELO, F. F.; AQUINO, A. C. M. M.; JUNIOR, A. B.; POLIZELLI, M. L. T. M. Screening of filamentous fungi for production of enzymes of biotechnological interest. Brazilian Journal of Microbiology, São Paulo, v. 37, n. 4, p. 474-480, 2006.

GUPTA, R.; GIGRAS, P.; MOHAPATRA, H.; GOSWAMI, V. K.; CHAUHAN, B. Microbial $\alpha$-amylases: biotechnological perspective. Process Biochemistry, London, v. 38, n. 11, p. 1-18, 2003.

GUPTA, S.; KAPOOR, M.; SHARMA, K. K.; NAIR, L. M.; KUHAD, R. C. Production and recovery of an alkaline exopolygalacturonase from Bacillus subtilis RCK under solid-state fermentation using statistical approach. Bioresource Technology, Essex, v. 98, n. 7, p. 2969-3180, 2007.
INSTITUTO BRASILEIRO DE GEOGRAFIA E ESTATÍSTICA - IBGE. Levantamento sistemático da produção agrícola. Pesquisa mensal de previsão e acompanhamento das safras agrícolas no ano civil. Rio de Janeiro, RJ: IBGE, v. 21, n. 12, p. 22-23, 2010.

IRFAN, M.; NADEEM, M.; SYED, Q. A.; BAIG, S. Submerged cultivation of Aspergillus niger on pretreated sugarcane bagasse. Word Journal of Agricultural Sciences, Oxford, v. 6, n. 4, p. 466-472, 2010.

KARMAKAR, M.; RAY, R. R. Extracellular endoglucanase production by Rhizopus oryzae in solid and liquid state fermentation of agro wastes. Asian Journal of Biotechnology, Tokio, v. 2, n. 1, p. 1-10, 2010.

KASHYAP, D. R.; VOHRA, P. K.; CHOPRA, S.; TEWARI, R. Applications of pectinases in the commercial sector: a review. Bioresource Technology, Essex, v. 77, n. 3, p. 215-227, 2001.

KATAPODIS, P.; CHRISTAKOPOULOU, V.; CHRISTAKOPOULOS, P. Optimization of xylanase production by Sporotrichum thermophil using corn cobs and response surface methodology. Engineering in Life Sciences, Weinheim, v. 6, n. 4, p. 410-415, 2006.

KNOB, A.; TERRASAN, C. R. F.; CARMONA, E. C. C. $\beta$-Xylosidase from filamentous fungi: an overview. World Journal of Microbiology and Biotechnology, Oxford, v. 26, n. 3, p. 389-407, 2010.

KUHAD, R. C.; GUPTA, R.; SINGH, A. Microbial cellulases and their industrial applications. Enzyme Research, London, v. 2011, p. 1-10, 2011.

LYND, L. R.; WEIMER, J.; VAN ZYL, W. H.; PRETORIUS, I. S. Microbial cellulose utilization: fundamentals and biotechnology. Microbiology and Molecular Biology Review, Washington, v. 66, n. 3, p. 506-577, 2002.

MALLER, A.; DAMÁSIO, A. R. L.; SILVA, T. M.; JORGE, J. A. J.; TERENZI, H. F.; POLIZELI, M. L. T. M. Biotechnological potential of agro-industrial wastes as a carbon source to thermostable polygalacturonase production in Aspergillus niveus. Enzyme Research, London, v. 2011, p. 1-6, 2011.

MILAGRES, A. M. F.; SANTOS, E.; PIOVAN, T.; ROBERTO, I. C. Production of xylanase by Thermoascus aurantiacus from sugar cane bagasse in an aerated growth fermentor. Process Biochemistry, London, v. 39, n. 11, p. 1387-1391, 2004.

MILLER, G. H. Use of dinitrosalicylic acid reagent for determination of reducing sugar. Annals of Chemistry, Washington, v. 31, n. 3, p. 426-429, 1959. 
MOURE,A.; GULLÓN, P.; DOMÍNGUEZ, H.; PARAJÓ, J. C. Advances in the manufacture, purification and applications of xylo-oligosaccharides as food additives and nutraceuticals. Process Biochemistry, London, v. 41, n. 9, p. 1913-1923, 2006.

MURUGAN, S.; ARNOLD, D.; PONGIYA, U. D.; NARAYANAN, P. M. Production of xylanase from Arthrobacter sp. MTCC 6915 using saw dust as substrate under solid state fermentation. Enzyme Research, London, v. 2011, p. 1-7, 2011.

MUSSATTO, S. I.; ROBERTO, I. C. Acid hydrolysis and fermentation of brewers' spent grain to produce xylitol. Journal of the Science of Food and Agriculture, Bognor Regis, v. 85, n. 14, p. 2453-2460, 2005.

MUSSATTO, S. I.; ROBERTO, I. C. Chemical characterization and liberation of pentose sugars from brewer's spent grain. Journal of Chemical Technology and Biotechnology, Oxford, v. 81, n. 3, p. 268-274, 2006.

NIGHOJKAR, S.; PHANSE, Y.; SINHA, D.; NIGHOJKAR, A.; KUMAR, A. Production of polygalacturonase by immobilized cells of Aspergillus niger using orange peel as inducer. Process Biochemistry, London, v. 41, n. 6, p. 1136-1140, 2006.

NITURE, S. K.; PANT, A. Purification and biochemical characterization of polygalacturonase II produced in semi-solid medium by a strain of Fusarium moniliforme. Microbiological Research, Jena, v. 159, n. 3, p. 305-314, 2004.

OMOJASOLA, P. F.; JILANI, O. P.; IBIYEMI, S. A. Cellulase production by some fungi cultured on pineapple waste. Nature and Science, New York, v. 6, n. 2, p. 64-79, 2008.

PALMA, M. B.; MILAGRES, A. M. F.; PRATA, A. M. R.; MANCHILHA, I. M. Influence of aeration and agitation rate on the xylanase activity from Penicillium janthinellum. Process Biochemistry, Oxford, v. 31, n. 2, p. 141-145, 1996.

PANDEY, A.; WEBB, C.; SOCCOL, C. R.; LARROCHE, C. Enzyme Technology. New Delhi: Asiatech Publishers, Inc, $2005.760 \mathrm{p}$.

PEDROLLI, D. B.; GOMES, E.; MONTI, R.; CARMONA, E. C. Studies on productivity and characterization of polygalacturonase from Aspergillus giganteus submerged culture using citrus pectin and orange waste. Applied Biochemistry and Biotechnology, Berlin, v. 144, n. 2, p. 191-200, 2008.

POLIZELI, M. L. T. M.; RIZZATI, A. C. S.; MONTI, R.; TERENZI, H. F.; JORGE, J. A.; AMORIN, D. S. Xylanases from fungi: properties and industrial applications. Applied Microbiology and Biotechnology, Berlin, v. 67, n. 5, p. 577-591, 2005.

PRATHYUSHA, K.; SUNEETHA, V. Bacterial pectinases and their potent biotechnological application in fruit processing/juice production industry: a review. Journal of Phytology, London, v. 3, n. 6, p. 16-19, 2011.

SANCHÉS, C. Lignocellulosic residues: biodegradation and bioconversion by fungi. Biotechnological Advances, Berlin, v. 27, n. 2, p. 185-194, 2009.

SEDMAK, J. J.; GROSSBERG, S. E. A rapid, sensitive, and versatile assay for protein using coomassie brilliant blue G250. Analytical Biochemistry, New York, v. 79, n. 1-2, p. 544-552, 1977.

SILVA, R.; LAGO, E. S.; MERHEB, C. W.; MACCHIONE, M. M.; PARK, Y. K.; GOMES, E. Production of xylanase and CMCASE on solid state fermentation in different residues by Thermoascus aurantiacus. Brazilian Journal of Microbiology, São Paulo, v. 36, n. 3, p. 235-241, 2005.

SIVARAMAKRISHNAN, S.; GANGADHARAN, D.; NAMPOOTHIRI, K. M.; SOCCOL, C. R.; PANDEY, A. $\alpha$ - Amylases from microbial sources - an overview on recent developments. Food Technology and Biotechnology, Zabreg, v. 44, n. 2, p.173-184, 2006.

SOUZA, P. M.; MAGAlHÃES, P. O. Application of microbial $\alpha$-amylase in industry - a review. Brazilian Journal of Microbiology, São Paulo, v. 41, n. 4, p. 850861, 2010.

SUKIMARAN, R. K.; REETA, R .S.; PANDEY, A. Microbial cellulases: production, applications and challenges. Journal of Scientific and Industrial Research, Washington, v. 64, n. 11, p. 832-844, 2005.

TERRASAN, C. R. F.; TEMER, B.; DUARTE, M. C. T.; CARMONA, E. C. Production of xylanolytic enzymes by Penicillium janczewskii. Bioresource Technology, Essex, v. 101, n. 11, p. 4139-4143, 2010.

TUNGA, R.; TUNGA, B. S. Extra-cellular amylase production by Aspergillus oryzae under solid state fermentation. International Center for Biotechnology. Japan: Osaka University, 2003. 12 p.

UNDERKLOFER, L. A.; BARTON, R. R.; RENNERT, S. S. Production of microbial enzymes and their applications. Applied Microbiology, New York, v. 6, n. 3, p. 212-221, 1958.

USTOK, F. I.; TARI, C.; GOGUS, N. Solid-state production of polygalacturonase by Aspergillus sojae ATCC 20235. Journal of Biotechnology, Amsterdam, v. 127, n. 2, p. 322-334, 2007. 
VIJAYARAGHAVAN, C. S.; REMYA, S.G.; PRAKASH， VOGEL， H. J. A convenient growth medium for V. Production of $\alpha$-amylase by Rhizopus microsporus Neurospora (Medium N). Microbiology Genetic Bull, using agricultural by-products in solid state fermentation. Research Journal of Microbiology, New York, v. 6, n. 4, p. 366-375, 2011.

ZHANG, P.; HIMMEL, M. E.; MIELENZ, J. R. Outlook for cellulase improvement: screening and selection strategies. Biotechnology Advances, Berlin, v. 24, n. 5, p. 452-481, 2006. 